\title{
Micro CT Analysis of Hard Tissue Debris Accumulation Created by SAF vs. ProTaper systems
}

\author{
Diyar Kh. Bakr ${ }^{(1)}$; Hussien F. Al-Hwaizi ${ }^{(2)}$; Raid F. Salman ${ }^{(3)}$
}

Background and objectives: Hard tissue debris is deposited routinely during root canal system instrumentation. A new instrument had been marketed with the aim of optimum shaping of all parts of the canal system, however, no information present about the amount of debris removal compared to conventional rotary system. This study investigated the amount of debris accumulated when the canal instrumented by SAF compared with ProTaper by using high resolution computed tomography (micro CT).

Methods: Twenty extracted single canalled teeth were utilized for this study; and randomly divided into 2 groups. In the first group, the root canals were prepared by using protaper rotary system till $\mathrm{F} 2$ and the root canal irrigated with $1 \mathrm{ml}$ of normal saline after each instrument. The root canals in the second group were prepared using SAF for $4 \mathrm{~min}$, with continuous irrigation (normal saline). After rescanning, the percentage value of total canal volume filled with hard tissue debris was calculated.

Results: For protaper instrumentation, a mean of $0.35 \%$ of the total canal system volume was filled with hard-tissue debris which was lesser than that of SAF system where a mean of $0.42 \%$ vol. was obtained. However, there was non-significant difference between them $(p=0.218)$ with in favor of the SAF system.

Conclusion: Root canal preparation with SAF-system resulted in more and effective hard tissue debris accumulation compared with protaper rotary files.

Keywords: Root canal preparation, SAF-system, ProTaper rotary files, Micro CT.

(1) B.D.S., M. Sc., Ph.D., Assistant Professor at the College of Dentistry- Hawler Medical University.
(2) B.D.S., M. Sc., Ph.D., Professor at the College of Dentistry- Baghdad University.
${ }^{(3)}$ B.D.S., M. Sc., Ph.D., Assistant Professor at the College of Dentistry- Hawler Medical University.

\section{Introduction}

The aim of root canal preparation is to shape the canals to an adequate geometry and clean the canal system by promoting access for disinfection solutions, this strategy has been termed chemo-mechanical canal preparation. ${ }^{1}$ The mechanical instrumentation of the root canal is an essential part of canal preparation. It facilitates the removal of pulp tissue and debris and enhance bacterial elimination but at the same time create a layer of organic and inorganic materials called smear layer. Different instrumentation systems are available to achieve these goals, despite variations in file design; technique and fabrication, significant portions of the root canal are remaining untouched with debris. ${ }^{2-5}$

A recently introduced file system is the self-adjusting file (SAF) is a fairly new concept in endodontic. It is hollow, thin-walled, compressible and pointed cylinder composed of $120 \mathrm{~mm}$ thick Ni Ti lattice. Metzger et $\mathrm{al}^{6}$ mentioned that when the file is inserted into the root canal, the instrument adapts 3-dimensionally to the root canal's 
longitudinal and cross-sectional shape. The surface of the lattice is slightly abrasive, and the system removes dentin with a vibrating, back-and-forth grinding motion. In addition, it has an inherent irrigation system in which the irrigant circulates through the hollow cylinder, enhancing the flow of irrigant that passes through the file. Previous research has shown that the SAF is effective in disinfecting ovalshaped root canals and also in the overall removal of debris and smear layer. ${ }^{7}$

The smear layer conventionally observed by scanning electron microscopy, during evaluation the root should be dried in ethanol and fractured. However, SEM provides limited information (two-dimensional images). The micro computed tomography is a high resolution scanning image with several promising applications in different fields of dentistry. In a recent methodological study, the possibility to quantitative assess inorganic debris in teeth was presented. In contrast to SEM studies on smear layer, this method is quantitative and three dimensional. The three dimensional smear layers observed on micro CT scans known as hard tissue debris. ${ }^{8,9}$

The aim of this study was to compare the efficacy of the SAF with the commonly used ProTaper rotary file system for the presence and accumulation of hard tissue debris within the root canal system by using micro computed tomography.

\section{Materials and methods}

Teeth selection. Twenty extracted anterior teeth were collected and stored in $0.1 \%$ thymol solution. The collected teeth had been de-coronated from their crown at cementenamel junction by using high speed diamond bur, in such way that the bur was perpendicular to the long axis of teeth. They were then accessed by using high speed diamond burs, the patency of the canal was confirmed and length of the root canal was determined with size \# $10 \mathrm{~K}$-files $(12 \mathrm{~mm}), \&$ specimens were randomly allocated to two groups with $\mathrm{N}$ : 10 for each. Then the entire tooth scanned by micro CT unit at an isotropic resolution of $35 \mu \mathrm{m}$ (SCANCO Medical, Switzerland).

Sample grouping. Group 1; root canal instrumentation with ProTaper; for the ProTaper preparation, 10 teeth were prepared with ProTaper Universal instruments driven at $250 \mathrm{rpm}$ with $2 \mathrm{~N} / \mathrm{cm}$ torque (X Smart, Dentsply, Maillefer). The sequence followed was S1 file (one third of working length) for 1 minute, S2 file (two third of working length) for 1 minute, F2 file (full working length) for 1 sec. Shaping S1 and S2 files were used in the canal with a brushing motion. Irrigation with $1 \mathrm{ml}$ normal saline was used between each instrument applied with a syringe (open end needle).

Group 2; root canal instrumentation with SAF; for the SAF preparation, 10 teeth were prepared with the SAF that was operated by using a trans-line (in and out) vibrating handpiece (GENTLE power, Kavo, Germany) combined with a RDT3 head (ReDent- Nova, Israel) at a frequency of $83.3 \mathrm{~Hz} \quad(5000$ movements per minute). This movement combined with intimate contact along the entire circumference and length of the canal and the slight rough surface of the file remove a layer of dentin with filing motion. The hollow design allows continuous irrigation with normal saline throughout the procedure. A special irrigation device (VATEA, ReDentNova) was connected to the irrigation hub on the file and provide flow of irrigation at flow rate of $4 \mathrm{ml} / \mathrm{min}$. The SAF inserted into the canal while vibrating and delicately advanced apically with an intermittent in and out movement until it reach a predetermined working length. It was operated with continuous irrigation and the preparation continued for 2 minutes. Then the teeth kept in container during transportation.

\section{Micro CT measurements and evaluations}

Specimens were scanned before and after preparation by using a commercially available micro computed tomography system $(\mu \mathrm{CT}$ 
35, SCANCO Medical, Switzerland). Teeth were scanned at $70 \mathrm{Kv}$ and $114 \mu \mathrm{A}$ with an isotropic resolution of $20 \mu \mathrm{m}$ resulting in 600 to 750 slices, covering a total of $12 \mathrm{~mm}$ for each root. Although the specimens were mounted on self-made holding fixture to ensure precise repositioning of the specimens into the scanning system; the mounting device ensured exact repositioning of the specimens for both pre and post scanning procedure. Superimposition was calculated subsequently with the software package IPL V5.15 (SCANCO Medical).

Hard tissue debris was identified and calculated subsequently with the software package IPL V5.15 (SCANCO Medical) voxels that were identified as soft tissue, liquid, or air (canal volume) in the preoperative scan, which then were identified as tooth material in the post-operative scan, were assumed to be filled with debris. Then subtract the post-operative volume from the preoperative volume results in a combined volume. The volume fraction of the preoperative scan only will then be identified as debris. For visualization of complete root canal before and after root canal preparation, the volume of interest for each tooth was selected. The accumulated hard tissue debris was superimposed on the original canal anatomy. Thus, accumulated hard tissue debris could be visualized in the root canals.

\section{Results}

Three dimensional reconstruction of the entire root canal system showed accumulated debris within the root canal. In group 1, instrumentation using ProTaper system left a mean $0.347 \%$ of the original canal system filled with hard tissue debris. While in group 2 , instrumentation using SAF system left a mean of $0.418 \%$ of the original canal system filled with hard tissue debris, (Fig. 1, 2, 3). Then the data were evaluated statistically with t-independent test, showed there were no significant differences between groups at $(\mathrm{p}=0.218),($ Table 1$)$.

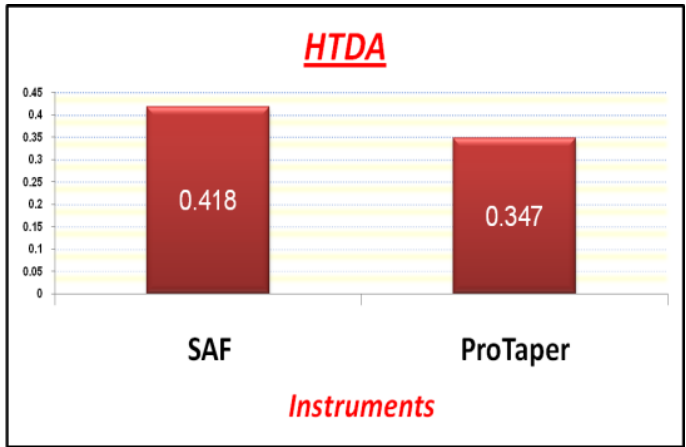

Figure 1: Bar chart for the difference between the two groups.

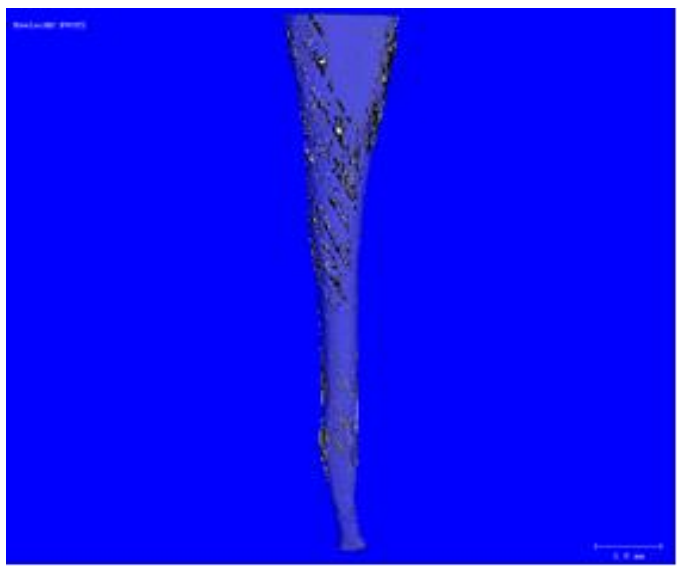

Figure 2: Photograph of micro CT of ProTaper system instrumented canal.

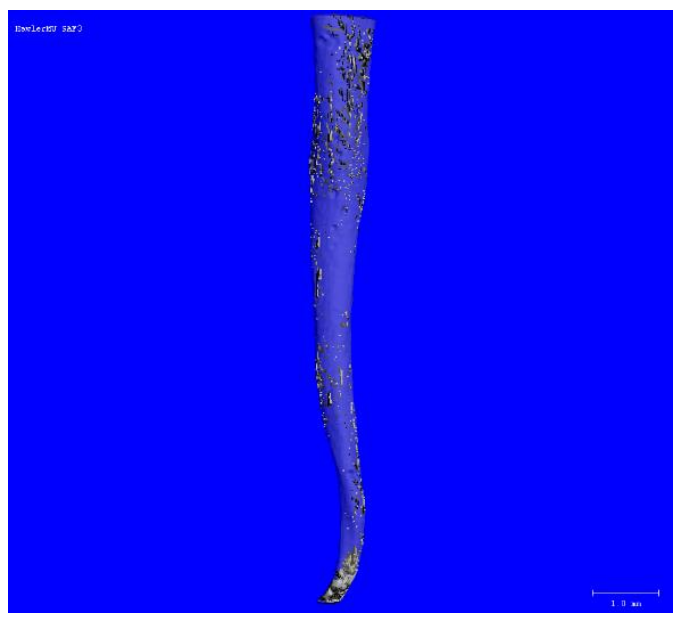

Figure 3: Photograph of micro CT of SAF system instrumented canal. 
Table 1: t-test for the difference between the two groups.

\begin{tabular}{|c|l|c|c|c|l|}
\hline Instrumentation & Mean & SD & SE & t-test & \multirow{2}{*}{ P-Value } \\
\cline { 1 - 4 } SAF & 0.418 & \pm .12 & .037 & \multirow{2}{*}{1.323} & \multirow{2}{*}{0.218} \\
\hline ProTaper & 0.347 & \pm .167 & .052 & & \\
\hline
\end{tabular}

\section{Discussion}

The success, reliability, and longevity of endodontic treatment is affected by endodontic files, rotary instrumentation, irrigants, and chelating agents. Controversy exists regarding the effectiveness of file system, irrigation techniques, irrigation solutions, chelating agents, and evaluation methods. ${ }^{10-11}$

The main purpose of this study was 2 folds: 1) the efficacy of file in removing the debris within the canal without using the $\mathrm{NaOCl}$ and chelating agents which are most widely used irrigant in root canal treatment based on it is capacity to dissolve necrotic tissue remnants and remove the smear layer from the root canal system. 2) Comparing the effectiveness of SAF system with continuous irrigation (normal saline) with ProTaper system with needle irrigation.

This study appears to be the first, in which the accumulation and subsequent removal of hard tissue debris during rotary instrumentation in single rooted teeth. Some previous micro CT studies (in which packing on dentin debris by rotary instrumentation); had examined without irrigation or with irrigations regime. The main goals these other studies are differ, in one pervious study, the goal obviously was to answer a baseline questions; Do rotary Ni Ti instruments create debris when cutting dentin and to discover what happen to this debris in the first place? ${ }^{8}$

In the other studies (more than one study), copious amounts of irrigating solutions ( $\mathrm{NaOCl}$ and EDTA) were used during and after instrumentation to determining the ability of irrigating solutions in removing the debris with instrumentation. ${ }^{9,12-13}$ In the present study, a step further was taken, the purpose was to answer a question; Do rotary $\mathrm{Ni} \mathrm{Ti}$ instrument remove debris when cutting dentin in root canal system when ( $\mathrm{NaOCl}$ and EDTA) not used. In the recent years, the resolution of micro CT has improved considerably from $81 \mu \mathrm{m}$ to $20 \mu \mathrm{m}$ and could provide nondestructive three dimensional images with high spatial resolution and unprecedented speed. The limitation of the current study is the fact that only hard tissue debris can be viewed; the remaining soft tissue is invisible. This is because micro CTs are based on radiographic images. As indicated in the Materials and Methods section, the volume of accumulated hard-tissue debris had to be related to the original canal volume and not to the canal volume after instrumentation for quantitative analysis. Many studies have demonstrated the limitation and challenge related to the many rotary systems regarding to shaping and cleaning the canal complexities. The concept of three dimensional file that adapts to the canal morphology is encourage. De-Deus et al ${ }^{14}$ histologically compared the debridement efficacy of the SAF system with protaper system, showed that SAF system was more efficient in pulpal debridement.

While Paranjpe et $a l^{15}$ microbiologically and microscopically compared the efficacy of SAF in cleaning and shaping oval canal, the result revealed an insufficient apical preparation and inadequate apical irrigation. Paque et $a l^{16}$ 
compared hard tissue debris accumulation by protaper system versus SAF system in mesial root canal of the mandibular molars, the result showed that SAF system resulted in less hard tissue debris accumulation in isthmuscontaining root canal systems compared with ProTaper rotary file. The result of the present study showed that there were no significant difference in debris accumulation between ProTaper system and SAF system, but the mean debris vol.\% of ProTaper system is slightly less than SAF system, this results may be related to using the normal saline that have no effect on organic and inorganic tissues. In the ProTaper system more than one file used and each one has the ability to remove debris of the canal by unique feature of the file (convex and triangular cross section). While in SAF system only one file used with hollow design that allow continuous irrigation with normal saline that may remove the debris due to continuation of fluid contact with canal wall with sonic activation and a scrubbing motion. In addition to that; the SAF system leaving more than $38 \%$ of the canal cross-section free for backflow of fluid and debris.

\section{Conclusion}

Root canal preparation with SAF-system resulted in comparable \& effective hard tissue debris removal compared with ProTaper rotary files.

\section{References}

1. Peters $\mathrm{O}$, Peters $\mathrm{C}$. Cleaning and shaping of root canal system. In: Cohen S, Hargreaves K, Keiser K. Pathways of the pulp, 9th ed. St Louis, MO Elsevier, 2006.

2. Haapasalo M, Endal U, Zandi H, Coil JM. Eradication of endodontic infection by instrumentation and irrigation solution in root canals. Endod Topics 2005; 10:77-102.

3. Peters OA, Paque F. Current developments in rotary root canal instrument technology and clinical use: a review. Quintessence Int 2010; 41:479-88.
4. Paque F, Ganahl D, Peter OA. Effects of root canal preparation on apical geometry assessed by microcomputed tomography. J Endod 2009; 35:1056-9.

5. Peters OA, Schonenberger K, Laib A. Effects of four $\mathrm{Ni} \mathrm{Ti}$ preparation techniques on root canal geometry assessed by micro-computed tomography. Int Endod J. 2001; 34:221-30.

6. Metzger Z, Teperovich E, Zary R, Cohen R, Hof R. The self-adjusting file (SAF): part 1- respecting the root canal anatomy: a new concept of endodontic files and its implementation. J Endod 2010; 36:679-90.

7. Siqueira JF Jr, Alves FR, Almeida BM, de Oliveira JC, Rocas IN. Ability of chemo-mechanical preparation with either rotary instruments or self-adjusting file to disinfect oval shaped root canals. J Endod 2010; 36; 1860-5.

8. Paque F, Laib A, Gautschi H, Zehnder M. Hard-tissue debris accumulation analysis by high-resolution computed tomography scans. J Endod 2009; 35:1044-7.

9. Paque F, Boessler C, Zehnder M. Accumulated hard tissue debris levels in mesial roots of mandibular molars after sequential irrigation steps. Int Endod J 2011; 44:148-53.

10. Zehnder M. Root canal irrigants. J Endod; 2006; 32:389-98.

11. Adigüzel Ö, Yiğit-Özer S, Kaya S, Uysal I, GanidağliAyaz S, Akkuş Z. Effectiveness of ethylenediaminetetraacetic acid (EDTA) and MTAD on debris and smear layer removal using a selfadjusting file. Oral Surg Oral Med Oral Pathol Oral Radiol Endod 2011; 112:803-8.

12. Paque F, Rechenberg D, Zehnder M. Reduction of hard tissue debris accumulation during rotary root canal instrumentation by etidronic acid in a sodium hypochlorite irrigant. J Endod 2012; 38:692-5.

13. Endal U, Shen Y, Knut A, Gao Y, Haapasalo M. A high-resolution computed tomographic study of changes in root canal isthmus area by instrumentation and root filling. J Endod 2011; 37: 223-7.

14. De-Deus G, Souza EM, Barino B, Maia J, Zamolyi RQ, Reis C. The self-adjusting file optimizes debridment quality in oval-shaped root canals. J Endod 2011; 37:701-5.

15. Paranjpe A, de Gregorio C, Gonzalez A. Efficacy of self-adjusting files system on cleaning and shaping oval canals: a microbiological and microscopic evaluation. J Endod 2012; 38:226-31. 
16. Paque F, Al-Jadaa A, Kfir A. Hard-tissue debris accumulation created by conventional rotary versus self-adjusting file instrumentation in mesial root canal systems of mandibular molars. Int Endod J 2012; 45:413-8. 